\title{
BMJ Open Social epidemiology of hypertension in Buffalo City Metropolitan Municipality (BCMM): cross-sectional study of determinants of prevalence, awareness, treatment and control among South African adults
}

\author{
Eyitayo Omolara Owolabi, ${ }^{1}$ Daniel Ter Goon, ${ }^{1}$ Oladele Vincent Adeniyi, ${ }^{2}$ \\ Eunice Seekoe ${ }^{1}$
}

To cite: Owolabi EO, Goon DT, Adeniyi $\mathrm{OV}$, et al. Social epidemiology of hypertension in Buffalo City Metropolitan Municipality (BCMM): crosssectional study of determinants of prevalence, awareness, treatment and control among South African adults. BMJ Open 2017;7:e014349. doi:10.1136/ bmjopen-2016-014349

- Prepublication history and additional material are available. To view, please visit the journal (http://dx.doi.org/ 10.1136/ bmjopen-2016-014349).

Received 18 September 2016 Revised 28 March 2017 Accepted 3 April 2017

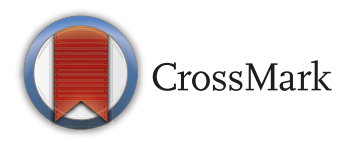

${ }^{1}$ Department of Nursing Science, Faculty of Health Sciences, University of Fort Hare, East London, South Africa

${ }^{2}$ Department of Family Medicine, Faculty of Health Sciences, Walter Sisulu University/Cecilia Makiwane Hospital, East London Hospital Complex, East London, South Africa

Correspondence to Eyitayo Omolara Owolabi; owolabiomolara101@gmail.com and Dr Oladele Vincent Adeniyi; vincoladele@gmail.com

\section{ABSTRACT}

Objectives This study examined hypertension prevalence, awareness, treatment and control and their determinants among adults attending health facilities in Buffalo City Metropolitan Municipality (BCMM) in the Eastern Cape. Design A cross-sectional analytical study.

Settings The three largest outpatient clinics in BCMM. Participants Ambulatory adults (aged 18 years and over) attending the study settings during the study period $(\mathrm{n}=998)$.

Primary outcome measure The prevalence of hypertension (systolic blood pressure (BP) of $\geq 140 \mathrm{~mm} \mathrm{Hg}$ and/or a diastolic BP of $\geq 90 \mathrm{~mm} \mathrm{Hg}$ or current medication for hypertension), the awareness of it (prior diagnosis of it) and its treatment and control (Eighth Joint National Committee Criteria of BP <140/90/90 mm Hg).

Secondary outcome measure Associated factors of hypertension, hypertension unawareness and uncontrolled hypertension.

Results Of the 998 participants included, the prevalence of hypertension was $49.2 \%$. Hypertension unawareness was reported by 152 participants (23.1\%) with significant gender difference $(p=0.005)$. Male sex, age $<45$ years, higher level of education, single status, current employment, higher monthly income, current smoking, alcohol usage, absence of diabetes and non-obese were significantly associated $(p<0.05)$ with hypertension unawareness. Of the participants who were aware of having hypertension $(n=339)$, nearly all $(91.7 \%, n=311)$ were on antihypertensive medication and only 121 participants (38.9\%) achieved the BP treatment target. In the multivariate logistic regression model analysis, ageing (95\% Cl 1.9 to 4.4$)$, being married ( $95 \% \mathrm{Cl} 1.0$ to 2.0$)$, male sex $(95 \% \mathrm{Cl} 1.2$ to 2.3$)$, concomitant diabetes $(95 \% \mathrm{Cl}$ 1.9 to 3.9$)$, lower monthly income $(95 \% \mathrm{Cl} 1.2$ to 2.2$)$, being unemployed ( $95 \% \mathrm{Cl} 1.0$ to 1.9$)$ and central obesity (95\% Cl 1.5 to 2.8) were the significant and independent determinants of prevalent hypertension.

Conclusion The prevalence and awareness of hypertension was high in the study population. In addition, the suboptimal control of BP among treated individuals, as well as the
Strengths and limitations of this study

- Large sample size of participants.

- First epidemiological data on hypertension prevalence, awareness, treatment and control in Buffalo City Metropolitan Municipality (BCMM).

- Survey was conducted in BCMM's three largest outpatient clinics.

- Findings should be treated with caution in view of the cross-sectional design and convenience sampling.

significant cardiovascular risk factors, warrant the attention of health authorities of BCMM and the country.

\section{INTRODUCTION}

Cardiovascular diseases (CVD) are the leading cause of death (17.3 million deaths) worldwide with a steep increase, especially in low-income and middle-income countries, and an $80 \%$ death toll prevalence. ${ }^{1}$ CVD have been predicted to account for about 23.6 million deaths by $2030 .^{2}$ Hypertension, one of the 10 leading contributors to the global burden of disease, is the most important modifiable risk factor for CVD and an independent risk factor for mortality worldwide $^{3-6}$ and has been described as a silent killer due to its asymptomatic nature among the sufferers. ${ }^{7}$ About 9 million people die from hypertension annually. ${ }^{8}$

The prevalence of hypertension in Africa has been reported in several studies. ${ }^{9-12}$ Hypertension was once considered a disease of affluence, but is now prevalent among the poor. ${ }^{13}$ In 2012, one in three adults were reported to be hypertensive, with the highest prevalence recorded in Africa $(50 \%) .^{14}$ 
South Africa is facing a serious burden of hypertension. ${ }^{15}$ More than 6.2 million South Africans are hypertensive; 3.2 million have a blood pressure $>160 / 90 \mathrm{~mm} \mathrm{Hg}$ and about 53 men and 78 women die daily from the effects of hypertension. ${ }^{16}$ Considering the pace of economic growth in South Africa, a further increase in the prevalence of hypertension is expected if drastic actions are not implemented in the country. ${ }^{1718}$ The treatment and control of hypertension are associated with a reduced incidence of complications, such as stroke, coronary heart disease and kidney disease. ${ }^{19-21}$

While the majority of individuals with hypertension remain undiagnosed, there is evidence indicating suboptimal control of blood pressure among individuals already in care for hypertension in South Africa. ${ }^{22-25}$ Many reasons have been advanced for the suboptimal treatment outcomes, such as socioeconomic and behavioural factors and health system factors. ${ }^{22}$ 26-28

In sub-Saharan Africa, the burden of hypertension is worsened by unreliable epidemiological data, underdiagnosis, poor treatment and uncontrolled hypertension. ${ }^{29-31}$ Epidemiological data help to inform public health policies for the prevention and control of hypertension. ${ }^{32}$ Likewise, prevention strategies, increased awareness, prompt detection, adequate treatment and control of blood pressure are basic requirements for a comprehensive approach for the reduction of hypertension, its complications and ultimately, its associated morbidity and mortality. ${ }^{33}$

There is a paucity of data on the prevalence, awareness and control of hypertension in the Eastern Cape, an understudied province in South Africa. Such vital epidemiological data are needed to inform policies on non-communicable diseases and resource distribution and for the crafting of effective interventions. This study attempts to bridge the gap by determining the prevalence and associated factors of hypertension, awareness and controlled hypertension among adults attending the three largest outpatient clinics in the Buffalo City Municipality, Eastern Cape, South Africa.

\section{METHODS}

\section{Study area and design}

This study analysed data from the Buffalo City Metropolitan Municipality (BCMM) Non-Communicable Disease Surveillance study. We selected the three largest outpatient clinics serving the residents of Buffalo City Municipality, South Africa. These clinics provide primary healthcare services for the 755200 residents of Buffalo City Municipality of Eastern Cape Province. ${ }^{34}$ All medical conditions except acute emergency cases present first at the primary healthcare facilities prior to upward referrals to secondary healthcare facilities. The family medicine outpatient clinic of Cecilia Makiwane Hospital and Nontyatyambo Community Health Centre provide primary healthcare services to the predominantly black South African residents of Mdantsane Township, a semi-urban community of Eastern Cape. Empilweni-Gompo Community Health Centre was the third facility, situated in Duncan Village, a suburban community of East London.

\section{Participants and sample size}

The sample size of the BCMM Non-Communicable Disease Surveillance study was based on the estimated proportion of individuals with hypertension in the population. We estimated a sample size of 1107 participants across the three study sites (369 per site) based on the hypertension prevalence rate of $40 \%$ in South Africa, ${ }^{23}$ allowing for a sampling error of $5 \%$ with a $95 \%$ confidence level.

All ambulatory individuals (patients and their family members) who fulfilled the inclusion criteria and were attending the study settings during the period of study were recruited into the study. All participants with abnormal findings agreed to be evaluated by the clinicians at the study settings. This study was conducted in April-May 2016. A convenience sampling method was used.

\section{Eligibility criteria}

Participants were included if aged $\geq 18$ years, attending the outpatient clinics of the selected hospital and community health centres, were willing to participate and had fasted in the 8 hours prior to recruitment into the study. Exclusion criteria included the acutely ill, psychotic, debilitated, pregnant or handicapped in any form such that obtaining anthropometric measurement would be difficult. A consecutive sample of 1107 participants took part in the study.

\section{Study instrument}

The participants were interviewed using the previously validated WHO STEPwise questionnaire, ${ }^{35}$ which comprises three major items: demographic and behavioural data, and measurements. The instrument was adapted locally and a pilot study, which included 20 participants at one of the sites, was conducted to validate its suitability to the local setting as well as to test the effectiveness of the research process. However, the results of the pilot study were not included in the main study.

\section{Ethical considerations}

Ethical approval was obtained in accordance with the Declaration of Helsinki II from the University of Fort Hare Research Ethics Committee and the Eastern Cape Department of Health, reference number; GOO061SOLO01. The management of the subdistrict department of health as well as the head of the respective health facilities gave permission prior to data collection. All participants provided written informed consent to participate in the study. Anonymity and confidentiality were ensured.

\section{Data collection procedure}

Data were obtained by personal interviews on demographic and behavioural characteristics and measurements of blood pressure, blood glucose and 
anthropometric parameters. Demographic variables included sex, age, marital status, level of education, employment status and average monthly income. Socioeconomic factors were measured by assessing the average monthly income, level of education and employment status. Participants were categorised as low-income earners if they earned Rand (R) 2000 or less per month, middle-income earners if they earned R2000-R5000 and high-income earners if they earned above R5000. Level of education was obtained by self-reporting of the highest grade level attained in school; levels were categorised as no formal education, primary (grade 1-7), secondary (grade 8-12) or tertiary (postsecondary). Participants were defined as unemployed if they reported that they were not employed in either the formal or informal sectors.

The following behavioural variables were obtained by self-reporting; cigarette smoking, alcohol use, physical activity and fruit and vegetables consumption patterns. Participants were questioned on their servings of fruit and vegetables daily. The smoking categories were primary smokers (smoking directly), secondary smokers (if living with a smoker) or non-smoker. Physical activity levels of participants were obtained by self-reporting and categorised based on their engagement in moderate (yes/no) or vigorous intensity (yes/no) exercise leading to an increase in heart rate and respiratory rate, such as gardening.

\section{Measurements}

Blood pressure (systolic and diastolic) was measured in accordance with standard protocols ${ }^{36}$ with a validated Microlife BP A100 Plus model. Hypertension was defined as an average of two systolic blood pressure of $\geq 140 \mathrm{~mm} \mathrm{Hg}$ and diastolic blood pressure of $\geq 90 \mathrm{~mm} \mathrm{Hg}$ in accordance with the Eighth Joint National Committee (JNC 8) criteria. Participants who reported being informed of their hypertensive status by health professional(s) were considered aware. Uncontrolled hypertension among those on treatment with at least one or more antihypertensive medications was defined as systolic blood pressure $\geq 140 \mathrm{~mm} \mathrm{Hg}$ and diastolic blood pressure $\geq 90 \mathrm{~mm} \mathrm{Hg}$, in accordance with JNC 8 criteria. The fasting blood glucose of each participant was measured with a validated ACCUCHEK glucose monitoring apparatus in fasting state. Participants were diagnosed with diabetes if their fasting blood glucose level was $\geq 7.0 \mathrm{mmol} / \mathrm{L}$ or if they were on current medications for diabetes. They were defined as prediabetic if the fasting blood glucose fell between 6.1 and $6.9 \mathrm{mmol} / \mathrm{L}^{37}$

Body weight was measured in light clothes to the nearest $0.01 \mathrm{~kg}$ in the standing position using a Soehnle Scale (Soehnle-Waagen GmbH, Murrhardt, Germany) and height was measured to the nearest $0.1 \mathrm{~m}$ by a stadiometer in standing position with closed feet (without shoes), holding their breath in full inspiration and Frankfurt line of vision. ${ }^{38}$ Body mass index (BMI) was calculated as weight in $\mathrm{kg}$ divided by height in square metres $\left(\mathrm{kg} / \mathrm{m}^{2}\right)$.
BMI was categorised in accordance with $\mathrm{WHO}^{39}$ as $<18.5$, $18.5-24.9,25.5-29.9$ and $>30.0 \mathrm{~kg} / \mathrm{m}^{2}$ as underweight, normal, overweight and obese, respectively.

\section{Statistical analysis}

Data were expressed as mean values \pm SD for continuous variables. Counts (frequencies $=\mathrm{n}$ ) and proportions $(\%)$ were reported for categorical variables. A bivariate analysis was used to examine variables that have a significant association with hypertension and a $\mathrm{p}$ value $<0.05$ was considered to be statistically significant. The significant variables were included in the binary logistic regression and were adjusted for confounding factors. Analysis was carried out at a $95 \%$ confidence level. Statistical analysis was performed with the Statistical Package for Social Science (SPSS) V.21 for windows (SPSS, Chicago, Illinois, USA).

\section{RESULTS}

Our analysis was based on 988 participants with complete data responses; 321 were males and 677 were females (response rate, 92\%). Eight per cent of the participants were excluded from the study because of incomplete documentation of blood pressure, blood glucose, weight or height. More than half of the respondents- $56.5 \%$ of males and $60.2 \%$ of females-were between the ages of 18 and 45 years. With respect to income level, $69.4 \%$ of men and $80.9 \%$ of women, either had no source of income or earned less than R2000 per month. Table 1 provides the descriptive characteristics of the participants.

\section{Prevalence, awareness and treatment of hypertension}

Of the 998 participants, $49.2 \% \quad(n=491)$ were diagnosed with hypertension (figure 1). Awareness of prior diagnosis of hypertension was reported by 339 participants (69.1\% of total hypertensive individuals). Among those aware of having hypertension, nearly all $(91.7 \%, \mathrm{n}=311)$ were on antihypertensive medication. Treatment to target blood pressure occurred in $38.9 \% \quad(n=121)$ of treated individuals.

\section{Factors associated with hypertension}

In bivariate analysis (table 2), the following risk factors were significantly associated with hypertension: ageing, male sex, lower level of education (below grade 8), being married, unemployed, lower income level, never drank alcohol, sedentary lifestyle and both central and overall obesity. BMI and age demonstrated positive linear associations with prevalent hypertension.

In the multivariate logistic regression model analysis (table 3), ageing, being married, male sex, concomitant diabetes mellitus, lower income level, being unemployed and central obesity were the significant and independent determinants of prevalent hypertension.

Factors associated with hypertension awareness and control Hypertension unawareness occurred in 152 participants with significant difference by sex $(p=0.005)$. The 
Table 1 Demographic characteristics of the participants by sex

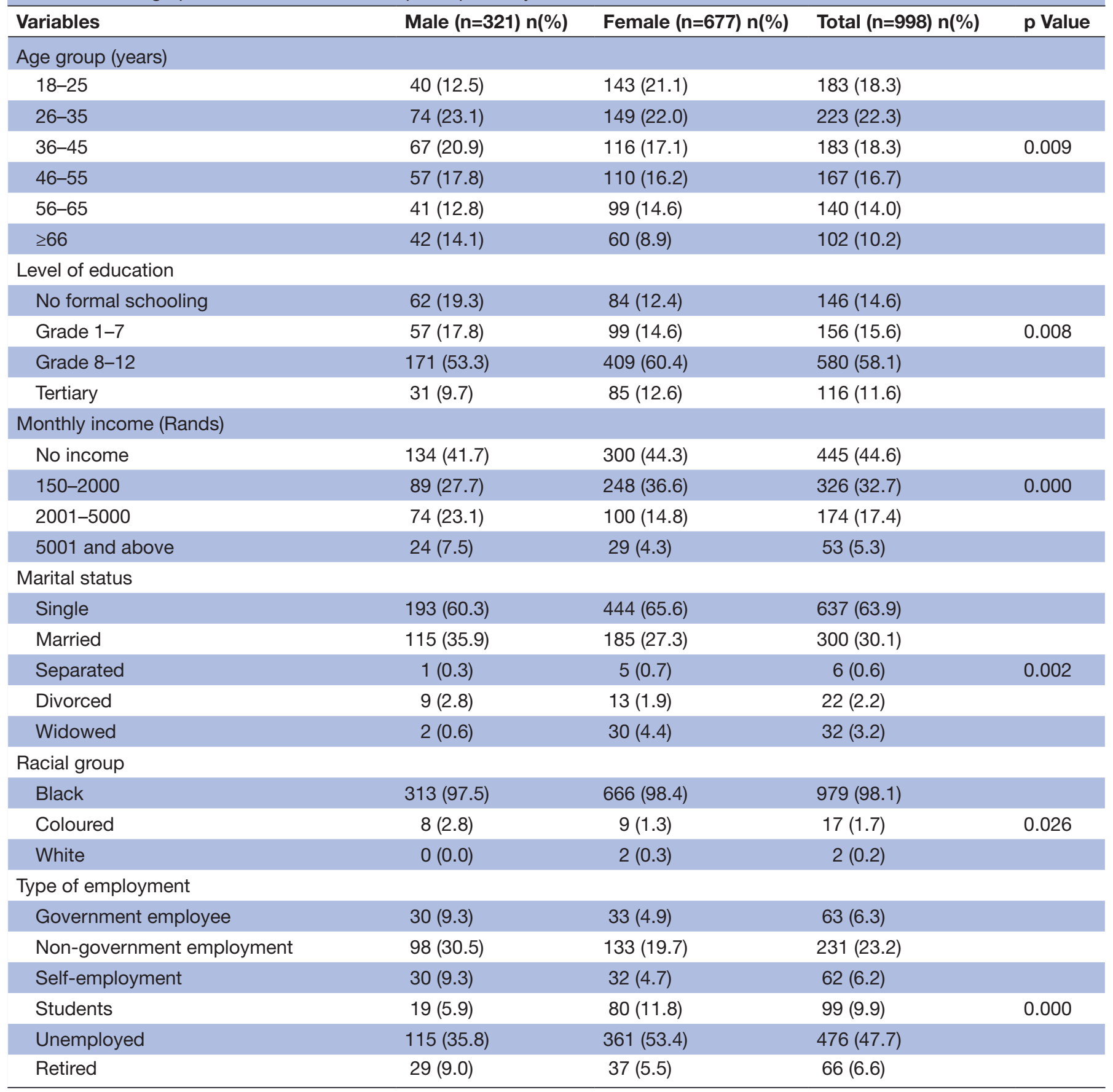

following factors were associated with hypertension unawareness in the study: male sex, lower age, higher level of education, single status, current employment status, higher income earners, current smokers, alcohol users, individuals with no diabetes and individuals with no obesity were associated with hypertension unawareness in the study (table 4).

Among the participants on treatment for hypertension $(n=311)$, only level of education (no formal schooling) was associated with uncontrolled hypertension. Concomitant diabetes mellitus was not significantly associated with uncontrolled hypertension (table 5).

\section{DISCUSSION}

To the best knowledge of the authors, this is the first paper addressing epidemiological gaps regarding the prevalence, awareness, treatment and control of hypertension in the BCMM. We found a high prevalence of hypertension $(49.2 \%)$ in our study population. There seems to be an upward trend in the prevalence of hypertension in the country which is rather unsurprising, given rapid urbanisation and its consequent effects on population health. Our result is higher than that in the study by Day $e t a l,{ }^{23}$ which reported a $40 \%$ prevalence of hypertension among South African adults in 2010. A lower 


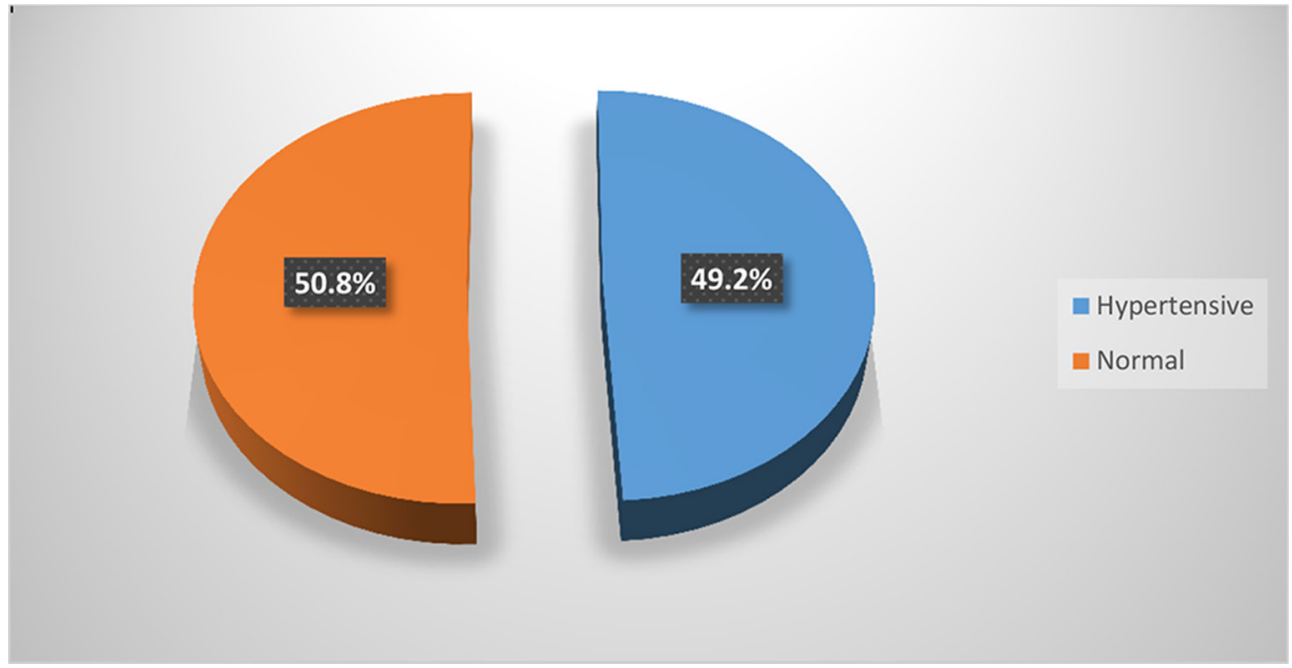

Figure 1 Prevalence of hypertension.

prevalence of hypertension $(38.9 \%)$ was reported by Peer et $a l^{25}$ among black urban South African adults between the ages of 24 and 65 years in Cape Town. A nationally representative household survey in South Africa which included individuals aged 15 years and above reported a prevalence range of $9 \%$ in Limpopo Province to $22.3 \%$ in Northern Cape Province. ${ }^{34}$ The highest prevalence of hypertension (12.4\%) was found among the black South African population. Weimann et a $t^{40}$ estimated a higher prevalence, at $37 \%$ and $52 \%$, in the Eastern Cape and Northwest Provinces. The higher prevalence of $49.2 \%$ found among our sample is comparable to Northwest Province's 52\%, but higher than the percentage reported for the Eastern Cape Province by Weimann et $a l^{40}$ with an almost similar age distribution. Our result was obtained from the primary healthcare setting and thus, may not be representative of the overall population. However, considering the age distribution of the study participants, with more than half below the age of 45 , such a high prevalence of hypertension further signifies the need for urgent interventions as population ageing is often associated with a higher prevalence of hypertension.

There is a wide variation in the prevalence of hypertension across sub-Saharan Africa; from 23\% among Zambian and Angolan adults to $26 \%$ in adults in four selected sub-Saharan African countries. ${ }^{10-12}{ }^{41}$ Akpan et $a t^{\ominus}$ reported a prevalence of $48.3 \%$ among rural adults in the eastern part of Nigeria, while a $44.7 \%$ prevalence was documented among rural Ghanaian adults. Similar trends of increasing hypertension prevalence have been reported worldwide; Chow et $a l^{30}$ found a prevalence of $40.8 \%$ among rural and urban dwellers in selected high-income countries (Canada, Sweden, United Arab Emirates), middle-income countries (Argentina, Brazil, Chile, Poland, Turkey, Malaysia, South Africa, China, Colombia and Iran) and low-income countries (Bangladesh, India, Pakistan and Zimbabwe). A higher prevalence was reported in certain other low-income and middle-income countries, with prevalence ranging from $50.7 \%$ to
$79.8 \%$ among adults living in urban areas of India, Latin America and China. ${ }^{42}{ }^{43}$ Our finding further supports the epidemiological shift of non-communicable diseases to low-income and middle-income nations. ${ }^{1344}$

Although a thorough comparison of various studies cannot be done as a result of differences in the definitions, methodology and populations used, the findings from this study indicate that South Africa is already at the forefront of the epidemiological transition. The shift is being exacerbated by advancements in technology attributed to urbanisation and westernisation. These are both the driving forces of the increasing burden of non-communicable disease risk factors of which hypertension is predominant. It is linked to the adoption of unhealthy lifestyle behaviours, poor dietary practices and poor engagement in physical activity, leading to obesity, and ultimately, cardiovascular risk factors like hypertension. Our findings signal a looming burden of non-communicable disease among the study participants if urgent actions are not taken.

We found ageing, male sex, being married, unemployment status, poverty, sedentary lifestyles, obesity and diabetes mellitus as the important determinants of prevalent hypertension in the study population. Several other studies have also established a link between these risk factors. Pires $e t a l^{12}$ affirmed that increasing age, lower level of education and increasing weight were associated with hypertension. Additionally, Guwatudde $e t a l^{11}$ found diabetes to be significantly associated with hypertension. Increasing age is often associated with changes in the body systems, including the cardiovascular system such as the heart and arteries. Old people suffer a great deal of cardiovascular risk factors, especially hypertension. ${ }^{45}$

We found a higher prevalence of hypertension in individuals with a lower level of education (below grade 8 ). These individuals are most likely to be unemployed and to earn $<$ R2000 per month. The association between level of education and health is rather complex; it can be assumed that the more educated an individual is, 
Open Access

Table 2 Bivariate analysis showing the associated risk factors for hypertension

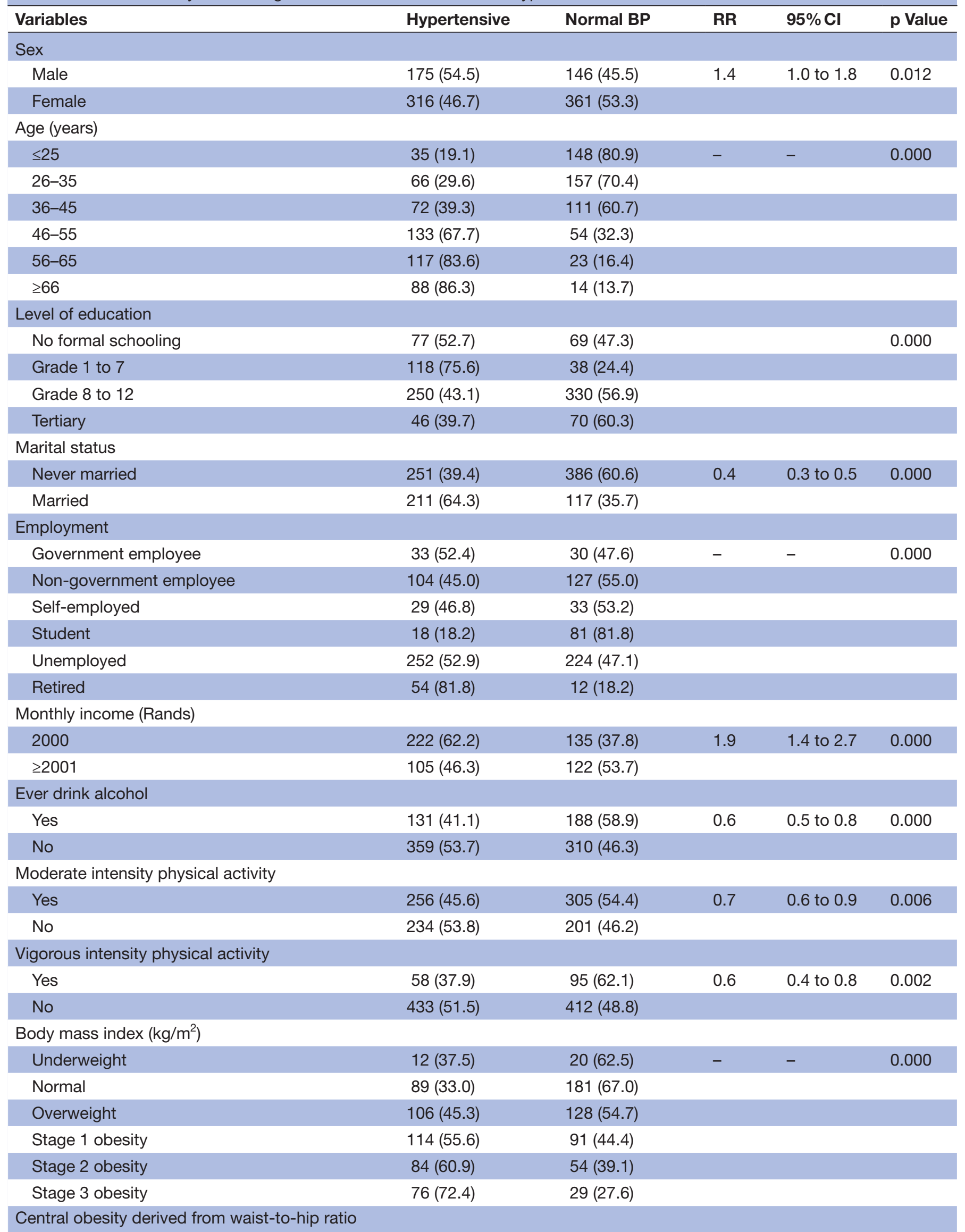

Continued 
Table 2 Continued

\begin{tabular}{|c|c|c|c|c|c|}
\hline Variables & Hypertensive & Normal BP & $\mathbf{R R}$ & $95 \% \mathrm{Cl}$ & p Value \\
\hline No & 221 (42.3) & $301(57.7)$ & & & \\
\hline Obese & $355(54.7)$ & $294(45.3)$ & 0.5 & 0.4 to 0.7 & 0.000 \\
\hline Not obese & 135 (38.9) & $212(61.1)$ & & & \\
\hline
\end{tabular}

$\mathrm{BP}$, blood pressure; $\mathrm{RR}$, relative risk.

the more knowledgeable he or she will be on matters of health. Whether this assumption is true in our study population is rather speculative. Cutler and Lleras-Muney ${ }^{46}$ reported that education increases knowledge. Educated individuals are more likely to be receptive to new developments, including newly approved drugs, and are often compliant with drug use. ${ }^{47}$ Our study participants with hypertension were poor and unemployed. Their socioeconomic status might have limited their access to healthy foods and increased their consumption of readily

Table 3 Multivariate logistic regression analysis showing the predictors of hypertension

\begin{tabular}{|c|c|c|c|c|}
\hline Variables & Beta & Wald & AOR $(95 \% \mathrm{Cl})$ & p Value \\
\hline \multicolumn{5}{|l|}{ Age (years) } \\
\hline \multicolumn{5}{|c|}{$\leq 26$ (reference) } \\
\hline Above 26 & 1.06 & 23.78 & $2.9(1.9$ to 4.4$)$ & 0.005 \\
\hline \multicolumn{5}{|l|}{ Marital status } \\
\hline \multicolumn{5}{|l|}{$\begin{array}{l}\text { Never married } \\
\text { (reference) }\end{array}$} \\
\hline Ever married & 0.39 & 5.89 & 1.5 (1.0 to 2.0$)$ & 0.015 \\
\hline \multicolumn{5}{|l|}{ Sex } \\
\hline \multicolumn{5}{|l|}{$\begin{array}{l}\text { Female } \\
\text { (reference) }\end{array}$} \\
\hline Male & 0.51 & 9.83 & 1.7 (1.2 to 2.3$)$ & 0.000 \\
\hline \multicolumn{5}{|c|}{ Diabetes mellitus } \\
\hline \multicolumn{5}{|l|}{ No (reference) } \\
\hline Yes & 1.01 & 31.6 & 2.7 (1.9 to 3.9$)$ & 0.000 \\
\hline \multicolumn{5}{|c|}{ Monthly income (Rands) } \\
\hline \multicolumn{5}{|c|}{$\begin{array}{l}\text { Middle income } \\
\text { >2000 (reference) }\end{array}$} \\
\hline $\begin{array}{l}\text { Low income } \\
\leq 2000\end{array}$ & 0.49 & 9.48 & 1.6 (1.2 to 2.2$)$ & 0.002 \\
\hline \multicolumn{5}{|l|}{ Employment } \\
\hline \multicolumn{5}{|l|}{$\begin{array}{l}\text { Employed } \\
\text { (reference) }\end{array}$} \\
\hline Unemployed & 0.33 & 4.01 & 1.4 (1.0 to 1.9$)$ & 0.045 \\
\hline \multicolumn{5}{|c|}{ Central obesity derived from waist circumference } \\
\hline \multicolumn{5}{|l|}{ No (reference) } \\
\hline Yes & 0.63 & 10.0 & 2.1 (1.5 to 2.8$)$ & 0.000 \\
\hline
\end{tabular}

AOR, adjusted OR. available, cheap foods which contribute to risk factors such as obesity and hypertension. This should, however, be interpreted with caution, as being unemployed does not necessarily denote a low income. Underlying factors associated with unemployment, such as psychological stress, could contribute to the high prevalence of hypertension among this cohort. We found a higher prevalence of hypertension among men. Female hormonal effect is believed to be protective ${ }^{49}$ and since the majority of the women in this study were below the age of 50 , this could be a plausible reason for our findings. Also, obesity, work stress, physical inactivity, alcohol intake and salt intake have been reported to be high in men, resulting in higher odds of men developing hypertension. ${ }^{50}$

There is a substantial intersection between hypertension and diabetes because of the shared metabolic pathway and risk factors. ${ }^{51-53}$ Hypertension is always found in more than half of individuals with type 2 diabetes and the chances of developing hypertension among persons with type 2 diabetes is more than double than that among persons with no diabetes. ${ }^{54}$ Also, as shown by Murphy et $a l$ and Bromfield and Munter, ${ }^{55}{ }^{56}$ there is a recognised link between hypertension, obesity, smoking, harmful use of alcohol and physical inactivity and a large percentage of the hypertension burden is attributed to these factors. The relationship between hypertension and obesity has long been established. Obesity increases the chance of developing hypertension and increases the risk of developing cardiovascular complications. ${ }^{57} 58$ As reported by Pandey $e t a l,{ }^{59}$ smoking increases the prevalence of hypertension. ${ }^{53}$ Physical inactivity is a precursor to obesity and hypertension. Physical inactivity is responsible for $20 \%$ of hypertension cases. ${ }^{60}$

The present study further illustrates that the majority $(69.1 \%)$ of the hypertensive patients were aware of their status, and of these, almost all $(91.7 \%)$ were already on treatment with only $38.9 \%$ achieving control. This awareness rate is higher than the $24 \%$ awareness rate reported among South Asian adults. ${ }^{61}$ There is a wide variation of hypertension awareness across African countries with rates ranging from $8 \%$ in Nigeria to $81 \%$ among elderly individuals in Tunisia. ${ }^{62}$ Also, the study settings being health facilities might have contributed to the high awareness prevalence recorded in this study.

Despite scientific successes in antihypertensive drug discoveries, achieving treatment targets remains a serious 
Table 4 Bivariate analysis showing the associated factors of hypertension awareness

\begin{tabular}{|c|c|c|c|c|c|}
\hline Variables & Aware & Unaware & $\mathbf{R R}$ & $95 \% \mathrm{Cl}$ & p Value \\
\hline \multicolumn{6}{|l|}{ Sex } \\
\hline Male & $108(61.7)$ & $67(38.3)$ & 0.6 & 0.4 to 0.9 & 0.005 \\
\hline Female & $232(73.4)$ & $84(26.6)$ & & & \\
\hline \multicolumn{6}{|l|}{ Age (years) } \\
\hline$<45$ & 79 (23.2.) & $95(54.6)$ & 0.5 & 0.1 to 0.3 & 0.000 \\
\hline$>45$ & $261(82.3)$ & $56(17.7)$ & & & \\
\hline \multicolumn{6}{|l|}{ Level of education } \\
\hline No formal schooling & $57(73.1)$ & $21(26.9)$ & - & - & 0.002 \\
\hline Grade 1-7 & $93(78.8)$ & $25(21.1)$ & & & \\
\hline Grade 8-12 & $168(67.2)$ & $82(32.8)$ & & & \\
\hline Tertiary & $22(48.9)$ & $23(51.1)$ & & & \\
\hline \multicolumn{6}{|l|}{ Marital status } \\
\hline Never married & $152(60.6)$ & $99(39.4)$ & 0.5 & 0.3 to 0.7 & 0.000 \\
\hline Married & $161(76.3)$ & $50(23.7)$ & & & \\
\hline \multicolumn{6}{|l|}{ Employment status } \\
\hline Employed & 99 (59.3) & $68(40.7)$ & 0.5 & 0.3 to 0.7 & 0.000 \\
\hline Unemployed & $241(74.4)$ & $83(25.6)$ & & & \\
\hline \multicolumn{6}{|l|}{ Monthly income (Rands) } \\
\hline$<2000$ & $276(71.7)$ & $109(28.3)$ & 1.7 & 1.1 to 2.6 & 0.018 \\
\hline$>2000$ & $64(60.4)$ & $42(39.6)$ & & & \\
\hline \multicolumn{6}{|l|}{ Current smokers } \\
\hline Yes & $33(50.0)$ & $33(50.0)$ & 0.4 & 0.2 to 0.7 & 0.000 \\
\hline No & 307 (72.2) & $118(27.8)$ & & & \\
\hline \multicolumn{6}{|l|}{ Ever drink alcohol } \\
\hline Yes & $67(50.8)$ & $65(49.2)$ & 0.3 & 0.2 to 0.5 & 0.000 \\
\hline No & $272(76.2)$ & $85(23.8)$ & & & \\
\hline \multicolumn{6}{|l|}{ Diabetes mellitus } \\
\hline Yes & $114(85.1)$ & $20(14.9)$ & & & \\
\hline No & $226(63.3)$ & $131(36.7)$ & 0.3 & 0.2 to 0.5 & 0.000 \\
\hline \multicolumn{6}{|l|}{ Obesity } \\
\hline Yes & $260(73.4)$ & $94(26.6)$ & 2.5 & 1.5 to 3.2 & 0.001 \\
\hline No & 79 (58.1) & 57 (41.9) & & & \\
\hline
\end{tabular}

$\mathrm{RR}$, relative risk.

challenge. Although nearly all of the participants with prior diagnosis were already receiving treatment for hypertension, a commendable effort, only $38.9 \%$ achieved treatment targets. This is somewhat better than previous studies conducted in Mthatha, South Africa $(25.5 \%)$ and Zimbabwe $(32.8 \%) .{ }^{22}{ }^{31}$ It is also comparable to the rate of control of hypertension $(36.4 \%)$ reported by Day et $a l^{23}$ in a household survey conducted among South African adults in 2010. Generally, hypertension control has been reported to be suboptimal in Africa, ranging from 2.6\% in Kenya to $42.2 \%$ in Ethiopia. ${ }^{62-64}$

We observed that men, those earning more than R2000 per month, those aged under 45 years, employed, cigarette smokers and alcohol users had higher rates of hypertension unawareness. Men have been reported to have higher odds of developing hypertension and the high rate of unawareness among them is not surprising. Females have been recognised as more likely to seek healthcare than men. ${ }^{65}$ Traditional gender roles in Africa account for the underutilisation of health facilities among men; men are the breadwinners and are perceived as healthy. ${ }^{66}$ Hence, they rarely visit health facilities for screening purposes unless they are sick. Hypertension is largely asymptomatic and this being the case, an affected individual will rarely seek healthcare. Our findings have serious public health consequences, due to the clustering of cardiovascular diseases among the individuals with hypertension unawareness. Younger individuals 
Table 5 Bivariate analysis showing the factors associated with hypertension control

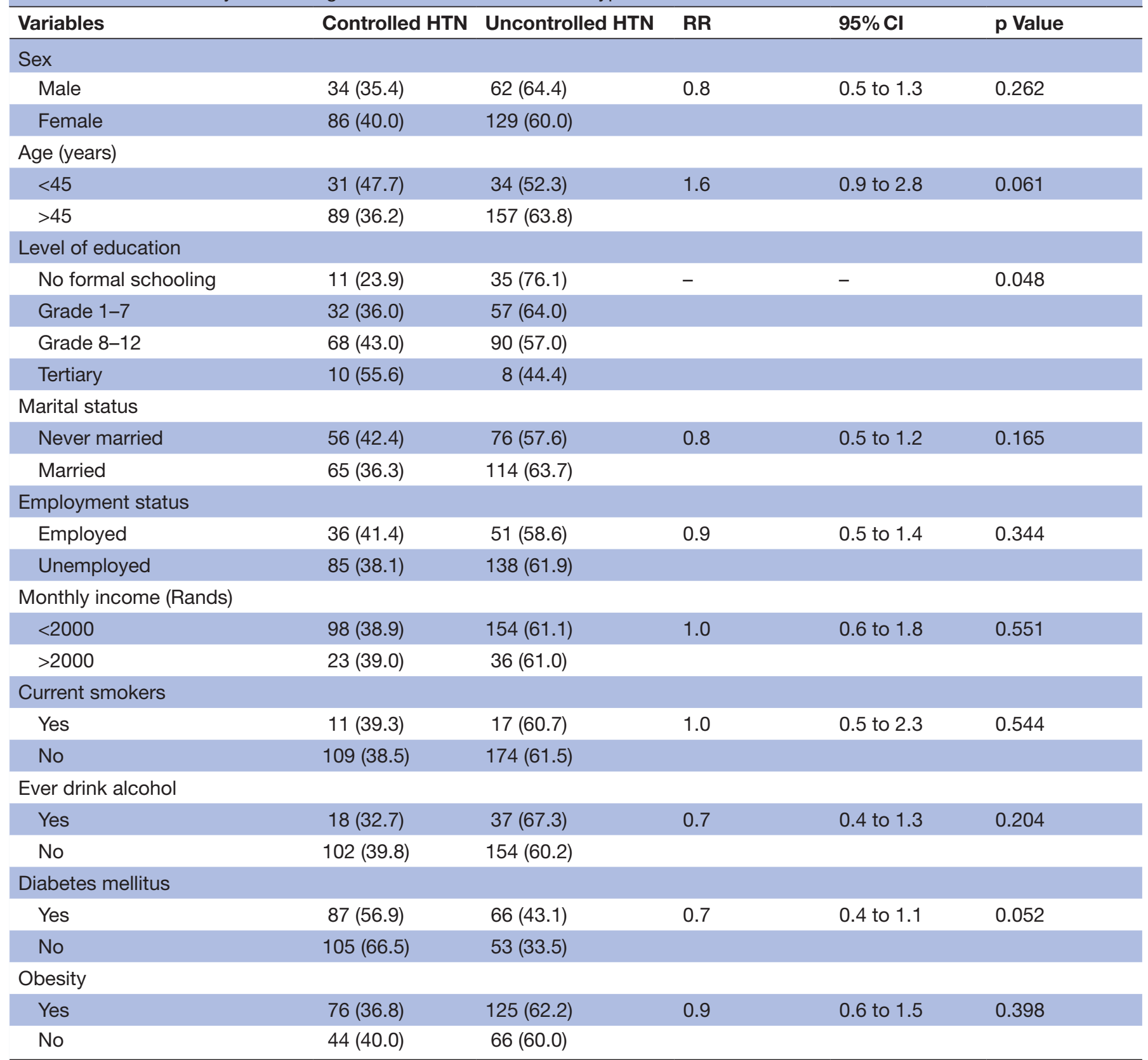

HTN, hypertension; RR, relative risk.

are unlikely to visit health facilities without any major sickness. Hence, the high rate of unawareness in those younger than 45 years. Besides, this cohort of individuals are preoccupied by their jobs. Older individuals tend to have multimorbidity and as such, would have had several opportunities to be screened for non-communicable diseases. Alcohol-dependence and nicotine-dependence may explain our findings of high unawareness among alcohol users and current cigarette smokers, respectively.

We found a high rate of uncontrolled hypertension $(62.4 \%)$ in our study participants. Several factors have been implicated for the poor control of hypertension in Africa, which are generally related to deficiencies in the healthcare system, non-adherence to medication regimens by patients and physicians' inertia to optimise treatment of hypertension. ${ }^{22}{ }^{62}$ Several studies have documented the unavailability of antihypertensive drugs as well as non-adherence to clinic visits by patients as a result of lack of transportation and time. ${ }^{126869}$ Poor treatment outcomes in Africa has been documented extensively. $^{13} 31627071$ In comparison, higher levels of control $(64.8 \%$ and $66 \%)$ of hypertension were reported in the USA and Canada, respectively. ${ }^{72} 73$ This is not a surprise as the management of hypertension is costly due to its chronic nature. High-income countries have been recording successes in the reduction of the burden related to hypertension and other non-communicable diseases. ${ }^{74}$ 
Also, participants who had diabetes mellitus were found to have a lower rate of controlled hypertension. Multimorbidity with significant risks of polypharmacy are some of the reasons for the poor control of blood pressure in those with concomitant diabetes. A study in a similar setting by Adeniyi et $a l^{22}$ found poor control of blood pressure among individuals with concomitant diabetes. Illiteracy was associated with poor blood pressure control among our study participants already on treatment for hypertension. Poor treatment outcomes among individuals with no formal education is not surprising. Despite the availability of medications at the health facility, some of our patients regularly miss appointments and fail to collect medications. Education is said to be 'power' and Cutler and Lleras-Muney ${ }^{46}$ assert that education increases knowledge. There is a possibility of a lack of adequate knowledge on the importance of medication use in the control of hypertension among illiterate persons. In addition, the benefits of positive lifestyle behaviours for the control of hypertension might not be fully appreciated by such individuals. Likewise, lack of education generally leads to poverty; thus, poorly educated patients are less likely to be able to purchase essential drugs for hypertension or to eat as healthily, as healthy foods tend to cost far more than low-cost, carbohydrate-rich foods. ${ }^{75}$

\section{Strengths and limitations}

The limitations of the study cannot be ignored. First, this was a cross-sectional study, hence causality cannot be ascribed to the determinants. Our findings should be interpreted with caution in view of the convenience sampling of the participants at the primary healthcare facilities. We also did not obtain information on the hypertensive medications being used and therefore, could not gain a full understanding of the uncontrolled hypertension in our study participants. Notwithstanding these limitations, the findings of the study provide useful epidemiological data in view of the large sample size, the large outpatient clinics selected and the previously understudied setting.

\section{CONCLUSION}

The findings of a high prevalence of hypertension and suboptimal blood pressure control of hypertension requires the urgent attention of health authorities in BCMM. Also, the clustering of cardiovascular risk factors in individuals with hypertension suggests that an integrated strategy addressing all the non-communicable diseases will be needed to mitigate the looming epidemic. Strategies aimed at the prevention of hypertension, its early diagnosis and treatment to target blood pressure levels are needed in BCMM. Also, the re-engineering of the primary healthcare system will be crucial towards dealing with the burden of non-communicable diseases in the region.

Correction notice This paper has been amended since it was published Online First. Owing to a scripting error, some of the publisher names in the references were replaced with 'BMJ Publishing Group'. This only affected the full text version, not the PDF. We have since corrected these errors and the correct publishers have been inserted into the references.

Acknowledgements The authors are grateful to the management and the nursing staff of the three health facilities for their support towards the successful implementation of the project.

Contributors E00, DTG and OVA conceptualised, designed and drafted the paper. ES participated in data collection and gave intellectual contribution into the manuscript. All authors read and approved the final manuscript.

Funding E00 received master's study grants from the National Research Foundation and the Health and Welfare Sector Education and Training Authority, South Africa towards the implementation of the project.

Competing interests None declared.

Patient consent Obtained.

Ethics approval University of Fort Hare Ethics Committee.

Provenance and peer review Not commissioned; externally peer reviewed.

Data sharing statement Data from this study will be made available on request.

Open Access This is an Open Access article distributed in accordance with the Creative Commons Attribution Non Commercial (CC BY-NC 4.0) license, which permits others to distribute, remix, adapt, build upon this work non-commercially, and license their derivative works on different terms, provided the original work is properly cited and the use is non-commercial. See: http://creativecommons.org/ licenses/by-nc/4.0/

(C) Article author(s) (or their employer(s) unless otherwise stated in the text of the article) 2017. All rights reserved. No commercial use is permitted unless otherwise expressly granted.

\section{REFERENCES}

1. WHO \& Global Health Observatory Data. Raisd Blood Pressure: situation and Trends. http://www.who.int/gho/ncd/risk_factors/ blood_pressure_prevalence_text/en/ (accessed 13 Jul 2015).

2. World Heart Federation. Urbanization and Cardiovascular Disease. Geneva, Switzerland, 2012.

3. Allen N, Berry JD, Ning H, et al. Impact of blood pressure and blood pressure change during middle age on the remaining lifetime risk for cardiovascular disease: the cardiovascular lifetime risk pooling project. Circulation 2012;125:37-44.

4. Bonifonte A, Ayer T, Veledar E, et al. Antecedent blood pressure as a predictor of cardiovascular disease. J Am Soc Hypertens 2015;9:690-6.

5. GBD 2015 Risk Factors Collaborators. Global, regional, and national comparative risk assessment of 79 behavioural, environmental and occupational, and metabolic risks or clusters of risks, 1990-2015: a systematic analysis for the Global Burden of Disease Study 2015. Lancet 2016;388:1659-714.

6. Sasai H, Sairenchi T, Irie F, et al. Long-term exposure to elevated blood pressure and mortality from cardiovascular disease in a Japanese population: the Ibaraki Prefectural Health Study. Hypertens Res 2011;34:139-44.

7. American Heart Association. What is high blood pressure. http:// www.heart.org/HEARTORG/Conditions/HighBloodPressure/ AboutHighBloodPressure/What-is-High-Blood-Pressure_UCM_30 1759_Article.jsp (accessed 13 Jul 2015).

8. Lim SS, Vos T, Flaxman AD, et al. A comparative risk assessment of burden of disease and injury attributable to 67 risk factors and risk factor clusters in 21 regions, 1990-2010: a systematic analysis for the Global Burden of Disease Study 2010. Lancet 2012;380:2224-60.

9. Akpan EE, Ekrikpo UE, Udo Al, et al. Prevalence of hypertension in Akwa Ibom State, South-South Nigeria: Rural versus Urban Communities Study. Int J Hypertens 2015;2015:1-5.

10. Díaz A, Ferrante D. Trends in prevalence of hypertension in Argentina in the last 25 years: a systematic review of observational studies. Rev Panam Salud Publica 2015;38:496-503.

11. Guwatudde D, Nankya-Mutyoba J, Kalyesubula R, et al. The burden of hypertension in sub-Saharan Africa: a four-country cross sectional study. BMC Public Health 2015;15:1211.

12. Pires JE, Sebastião YV, Langa AJ, et al. Hypertension in Northern Angola: prevalence, associated factors, awareness, treatment and control. BMC Public Health 2013;13:90.

13. van de Vijver S, Akinyi $\mathrm{H}$, Oti S, et al. Status report on hypertension in Africa-consultative review for the 6th session of the African Union Conference of Ministers of Health on NCD's. Pan Afr Med J 2013;16:1-17. 
14. World Health Organization. New study highlights higher hypertension, diabetes incidences. Media Centre. http://www.who.int/mediacentre/ news/releases/2012/world_health_statistics_20120516/en/ (accessed 29 Jan 2016).

15. Hasumi T, Jacobsen KH. Hypertension in South African adults: results of a nationwide survey. J Hypertens 2012;30:2098-104.

16. Rayner B. What is the prevelance of hypertension? Health 24 hypertension, 1. http://www.health24.com/Medical/Hypertension/ Faqs/What-is-the-prevalence-of-hypertension-20130205 (accessed 3 Jul 2016)

17. Africa Ranking. Ten most developed countries in Africa. http://www. africaranking.com/most-developed-african-countries/ (accessed 30 Jun 2016)

18. AnswersAfrica. Ten most technologically advanced countries in Africa. Timeless. 2014. http://answersafrica.com/top-10-mosttechnologically-advanced-countries-in-africa.html/2

19. Beckett NS, Peters R, Fletcher AE, et al. Treatment of hypertension in patients 80 years of age or older. N Engl J Med 2008;358:1887-98.

20. Ninomiya T, Perkovic V, Turnbull F, et al. Blood pressure lowering and major cardiovascular events in people with and without chronic kidney disease: meta-analysis of randomised controlled trials. $B M J$ 2013;347:1-15

21. Cushman WC, Evans GW, Byington RP, et al. Effects of intensive blood-pressure control in type 2 diabetes mellitus. N Engl J Med 2010;362:1575-85.

22. Adeniyi OV, Yogeswaran P, Longo-Mbenza B, et al. Uncontrolled hypertension and its determinants in patients with concomitant Type 2 Diabetes Mellitus (T2DM) in Rural South Africa. PLoS One 2016;11:0150033:e0150033.

23. Day C, Groenewald P, Laubscher R, et al. Monitoring of noncommunicable diseases such as hypertension in South Africa: challenges for the post-2015 global development agenda. S Afr Med J 2014:104:680.

24. Mayosi BM, Flisher AJ, Lalloo UG, et al. The burden of non-communicable diseases in South Africa. The Lancet 2009;374:934-47.

25. Peer N, Steyn K, Lombard C, et al. A high burden of hypertension in the urban black population of Cape Town: the cardiovascular risk in Black South Africans (CRIBSA) study. PLoS One 2013;8:e78567.

26. Damasceno A, Azevedo A, Silva-Matos C, et al. Hypertension prevalence, awareness, treatment, and control in mozambique: Urban/Rural gap during epidemiological transition. Hypertension 2009;54:77-83.

27. de Munter JS, Hu FB, Spiegelman D, et al. Whole grain, bran, and germ intake and risk of type 2 diabetes: a prospective cohort study and systematic review. PLoS Med 2007;4:e261.

28. Kearney PM, Whelton M, Reynolds K, et al. Global burden of hypertension: analysis of worldwide data. Lancet 2005;365:217-23.

29. Addo J, Smeeth L, Leon DA. Hypertension in sub-saharan Africa: a systematic review. Hypertension 2007;50:1012-8.

30. Chow C, Teo K, Rangarajan S, et al. Prevalence, awareness, treatment, and control of hypertension in Rural and Urban Communities in High-, Middle-, and Low-Income Countries. J Am Med Assoc 2013;3:9.

31. Goverwa TP, Masuka N, Tshimanga M, et al. Uncontrolled hypertension among hypertensive patients on treatment in Lupane District, Zimbabwe, 2012. BMC Res Notes 2014;7:703.

32. Taylor B, Irving HM, Baliunas D, et al. Alcohol and hypertension: gender differences in dose-response relationships determined through systematic review and meta-analysis. Addiction 2009;104:1981-90.

33. Meredith PA, Ostergren J. From hypertension to heart failure -- are there better primary prevention strategies? J Renin Angiotensin Aldosterone Syst 2006; 7:64-73.

34. Statistics South Africa. South African Statistics. 1-190. http://www. statssa.gov.za/publications/SAStatistics/SAStatistics2011.pdf.

35. World Health Organization (2003). Distribution : general steps : a framework for surveillance the WHO STEPwise approach to Surveillance of noncommunicable diseases (STEPS). Geneva. http:// www.who.int/.surveillance/./steps framework dec03.pdf.

36. Seedat $Y$, Rayner B, Veriana Y. South African hypertension practice guideline 2014. Cardiovasc J Afr 2014;6:288-94.

37. Amod A, Motala A, Levitt N, et al. Type 2 Diabetes Guideline. JEMDSA 2012;17:S1-94.

38. Marfell-Jones N, Olda T, Stew A. International standards for anthropometric assessment. Australia: The international Society for the Advancement of Kinanthropometry, 2006.

39. World Health Organization. Definition, diagnosis \& classification of diabetes mellitusand its complications: report of a WHO Consultation. Part 1: diagnosis andclassification of diabetes mellitus. Geneva: WHO, 1999. http://www.who.int/mediacentre/factsheets/fs311/en/.
40. Weimann A, Dai D, Oni T. A cross-sectional and spatial analysis of the prevalence of multimorbidity and its association with socioeconomic disadvantage in South Africa: a comparison between 2008 and 2012. Soc Sci Med 2016;163:144-56.

41. Yan LD, Chi BH, Sindano N, et al. Prevalence of hypertension and its treatment among adults presenting to primary health clinics in rural Zambia: analysis of an observational database. BMC Public Health 2015;15:1-9.

42. Manimunda S, Attayuru P, Vivek B, et al. Association of hypertension with risk factors \& hypertension related behaviour among the aboriginal nicobarese tribe living in Car nicobar Island, India. Int $J$ Med Res 2011;133:287-93.

43. Prince M, Ebrahim S, Acosta D, et al. Hypertension prevalence, awareness, treatment and control among older people in Latin America, India and China: a 10/66 cross-sectional population-based survey. J Hypertens 2010;30:177-87.

44. World Health Organization. Cardiovascular Diseases. Factsheet: Cardiovascular Diseases. http://www.who.int/mediacentre/ factsheets/fs317/en/ (accessed 29 Jan 2015).

45. McDonald M, Hertz RP, Unger AN, et al. Prevalence, awareness, and management of hypertension, Dyslipidemia, and Diabetes among United States adults aged 65 and older. J Gerontol A Biol Sci Med Sci 2009;64A:256-63.

46. Cutler DM, Lleras-Muney A. Understanding differences in health behaviors by education. J Health Econ 2010;29:1-28.

47. Deaton A, Cutler D, Lleras-Muney A. The determinants of mortality. $J$ Econ Perspect 2006;20:97-120.

48. Foster AD, Rosenzweig MR, Mark R. Microeconomics of technology adoption. Annu Rev Econom 2010;2:395-424.

49. Reckelhoff JF. Gender differences in the regulation of blood pressure. Hypertension 2001;37:1199-208.

50. Exchange $\mathrm{H}$. High blood pressure: how do men and women Differ? Managing Chronic Illnesses. http://www.healthxchange.com.sg/he althyliving/ManagingChroniclllnesses/Pages/high-blood-pressurehow-do-men-and-women-differ.aspx (accessed 15 Jul 2016).

51. Cheung BMY. The hypertension-diabetes continuum. J Cardiovasc Pharmacol 2010;55:333-9.

52. Cheung BMY, Wat NMS, Tso AWK, et al. Association between raised blood pressure and dysglycemia in Hong Kong Chinese. Diabetes Care 2008;31:1889-91.

53. Cheung BMY, Li C. Diabetes and hypertension: is there a common metabolic pathway? Curr Atheroscler Rep 2012;14:160-6.

54. Landsberg L, Molitch M. Diabetes and hypertension: pathogenesis, prevention and treatment. Clin Exp Hypertens 2004;26(7-8):621-8.

55. Murphy GA, Asiki G, Ekoru K, et al. Sociodemographic distribution of non-communicable disease risk factors in rural Uganda: a crosssectional study. Int J Epidemiol 2013;42:1740-53.

56. Bromfield S, Muntner P. NIH Public Access. Curr Hypertens Rep 2014;15:134-6.

57. Chiang B, Perlman L, Epstein F. Overweight and hypertension. Circulation 1969. XXXIX

58. Landsberg L, Aronne LJ, Beilin LJ, et al. Obesity-related hypertension: pathogenesis, cardiovascular risk, and treatment. $J$ Clin Hypertens 2013;15:14-33.

59. Pandey A, Patni N, Sarangi S, et al. Association of exclusive smokeless tobacco consumption with hypertension in an adult male rural population of India. Tob Induc Dis 2009;5:15.

60. World Economic Forum. From burden to "Best Buys": Reducing the Economic Impact of Non-Communicable Diseases in Low- and Middle-Income Countries. Geneva, Switzerland, 2012.

61. Shah SM, Loney T, Sheek-Hussein M, et al. Hypertension prevalence, awareness, treatment, and control, in male south asian immigrants in the United Arab Emirates: a cross-sectional study. BMC CardiovasC Disord 2015:15:1-11.

62. Kayima J, Wanyenze RK, Katamba A, et al. Hypertension awareness, treatment and control in Africa: a systematic review. BMC Cardiovasc Disord 2013;13:54.

63. Bosu W. Epidemic of hypertension in Ghana : a systematic review. BioMed Central. Public Health 2010;10:418.

64. Hendriks ME, Wit FW, Roos MT, et al. Hypertension in Sub-Saharan Africa: cross-sectional surveys in four rural and Urban communities. PLoS One 2012;7:e32638.

65. Adeniyi OV, Longo-Mbenza B, Ter Goon D. Female sex, poverty and globalization as determinants of obesity among rural South African type 2 diabetics: a cross-sectional study. BMC Public Health 2015;15:298.

66. Peacock D, Redpath J, Weston M, et al. Literature review on men, gender, health and HIV and AIDS in South Africa. Johannesburg, South Africa, 2008.

67. Springer K, Mouzon D. "Macho men" and preventive health care: Implications for older men in different social classes. J Health Soc Behav 2011;52:212-27. 
68. Oladapo OO, Salako L, Sodiq O, et al. Cardiovascular Topics a prevalence of cardiometabolic risk factors among a rural Yoruba South-Western Nigerian population: a population-based survey. Cardiovasc J Afr 2010;21:26-31.

69. Ulasi II, ljoma CK, Onodugo OD. A community-based study of hypertension and cardio-metabolic syndrome in semi-urban and rural communities in Nigeria. BMC Health Serv Res 2010;10:71.

70. Ong KL, Cheung BMY, Wong LYF, et al. Prevalence, treatment, and control of diagnosed diabetes in the U.S. National Health and Nutrition Examination Survey 1999-2004. Ann Epidemiol 2008;18:222-9.

71. Thiyane K, Mothebe T, Sooro M, et al. An observational study of hypertension treatment and patient outcomes in a primary care setting. PAMJ 2011;20:1-10.
72. Angell S, Garg R, Gwynn R, et al. Control of hypertension in New York City. Circulation Cardiovascular Quality Outcomes 2008;1:46-53.

73. Joffres M, Falaschetti E, Gillespie C, et al. Hypertension prevalence, awareness, treatment and control in national surveys from England, the USA and Canada, and correlation with stroke and ischaemic heart disease mortality: a cross-sectional study. BMJ Open 2013;3:e003423.

74. World Health Organization. Global health risks: progress and challenges. Geneva, Switzerland, 2009 http://www.who.int/ healthinfo/global_burden_disease/GlobalHealthRisks_report_full. pdf.

75. Chris A, Fleisher L, Hatt L, et al. Health financing in Africa today : challenges and Opportunities. Washington, DC, 2008. 